\title{
Negotiating Climate and Energy Futures: Prospects for Climate Compatible Recoveries in Latin America and the Caribbean
}

Nora Hampl ( $\square$ norah16@univie.ac.at)

University of Vienna https://orcid.org/0000-0002-0862-9327

\section{Short Report}

Keywords: Latin America and the Caribbean, LAC, climate change, energy solutions, energy policy, transitions, rural, urban, renewable energy, the Paris Agreement, sustainable development, innovation, training, capabilities, equity

Posted Date: November 1st, 2021

DOI: https://doi.org/10.21203/rs.3.rs-1037215/v1

License: (a) (i) This work is licensed under a Creative Commons Attribution 4.0 International License. Read Full License 


\begin{tabular}{|c|c|}
\hline 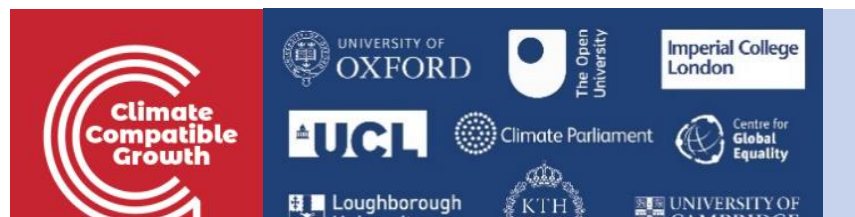 & 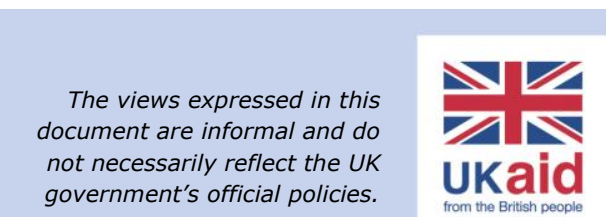 \\
\hline
\end{tabular}

\title{
Negotiating Climate and Energy Futures: Prospects for Climate Compatible Recoveries in Latin America and the Caribbean
}

\author{
Nora Hampl
}

\section{Key Messages:}

- Avoid a "race to the bottom" choose climate compatible growth (CCG) over energy-intensive growth

- Improve legal frameworks for the uptake of renewables

- Improve local capabilities to ensure localized benefits over the long term

- Establish RTCs (Research \& Training Centres) to communicate, demonstrate, and implement CCG solutions

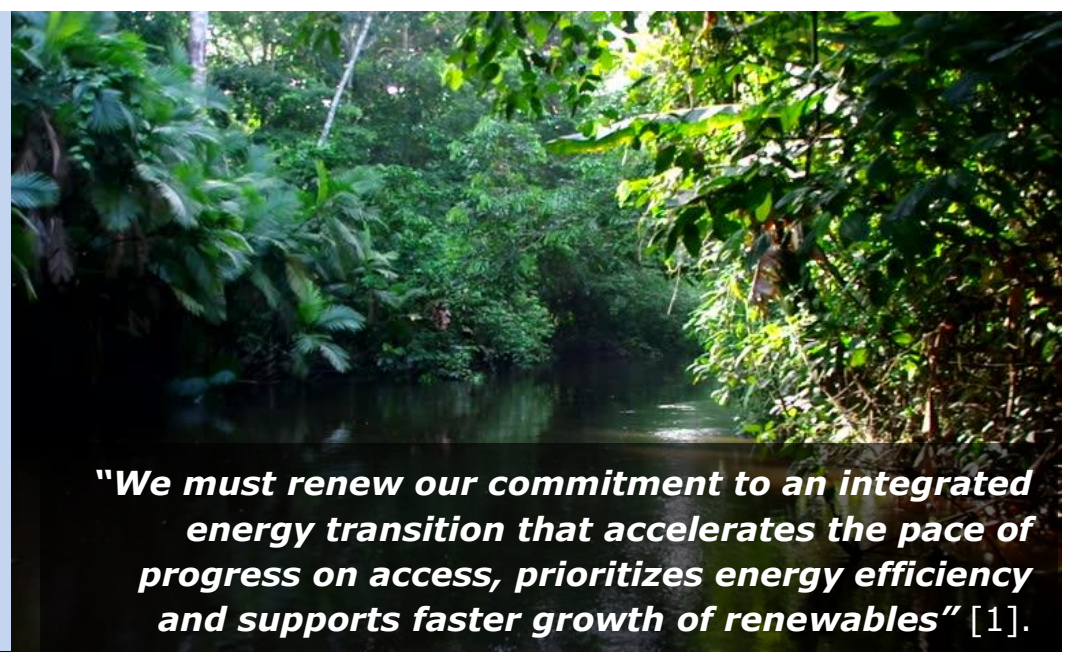

\section{Introduction}

This policy brief juxtaposes current approaches to economic recovery in Latin America and the Caribbean (LAC) against an ideal type - climate compatible recovery aligned with the Paris Agreement and the 2030 Agenda. Two questions are posed: first, as LAC countries attempt to balance their budgets in response to the economic contraction due to the pandemic, will this result in spending cuts that will undermine more ambitious climate goals and sustainable energy targets? Second, how do international organizations, donor agencies, and funding institutions propose to address challenges to clean energy transitions faced by the LAC region?

The findings summarize present-day challenges and differentiate between factors that are likely to push LAC toward development trajectories that replicate past uneven distribution of costs and benefits and factors that are likely to improve livelihood prospects for many, including those currently left-behind.

As a world region, LAC is still a world leader in clean energy use. It is also a region with a high concentration of cities severely impacted by climate change. Climate vulnerability manifests in both urban and rural areas (heat extremes, changing precipitation, declines in hydrological systems' viability, and erosion of natural habitats and biodiversity).

Climate compatible energy transitions are deemed essential for slowing down the pace of climate change and limiting the rise of global temperatures, but LAC's economic downturn in the aftermath of the pandemic poses serious risk for climate compatible recoveries (Table $\mathbf{1}$ ).

Table 1. LAC is the region hit the hardest by the pandemic

- US\$ 113 billion lost in tax revenues ( $=59 \%$ of regional spending on public health)

- $20 \%$ drop in remittances

- $25 \%$ fall in foreign direct investment \& trade

- $8 \%$ decline in GDP

- 4 million people slipped into extreme poverty (work lost in the informal sector) 


\section{Fossill fuels or renewables?}

Even though LAC as a world region has more renewables in the energy mix than other world regions, the expansion of megacities has resulted in greater consumption of fossil fuels, contributing to high levels of ambient pollution, poor health, and environmental degradation. While per capita $\mathrm{CO}_{2}$ emissions are still lower in LAC than in the rest of the world, the growing energy demand-double that of world average-prompts a question whether this increase will be met by an increase in fossil fuel energy production and supply, or predominantly by renewables [2]. Central America, Mexico, and the Caribbean still rely heavily on fossil fuels, and other countries are beginning to replace renewables with fossil fuels, particularly in electricity production. Gas-fired generation is the most significant source of electricity after hydropower, accounting for $25 \%$ of power generation [3].

\section{Key findings}

Based on the document analysis, recovery packages that focus on decoupling economic growth from GHG (greenhouse gas) emissions and ecosystem degradation have the advantage of comprehensively addressing the aggregate negative effects of the pandemic, biodiversity loss, and climate change.

In post-COVID recoveries, Latin America needs to avoid a "race to the bottom" and carefully weigh the risks of energy-intensive development against climate-compatible development alternatives [4-6].

While a faster uptake of renewables seems to be overwhelmingly favoured by international agencies, the following question remains unanswered - which renewables, and at what scale, should be implemented to meet the demand, and at the same time deliver multiple benefits to socially and culturally diverse communities, including those currently without access? (Table $\mathbf{2}$ ).

\section{Table 2. Communities left behind}

- 350 million lack access to safe sanitation

- 160 million lack access to safe water

- 50 million lack access to cooling

- 22 million lack access to electricity

- $80 \%$ of total population live in urban areas

- $50 \%$ of indigenous population live in cities
For renewable technologies to achieve high levels of social acceptance across diverse societal groups, and to reach communities living in remote areas, more effective ways of communicating the benefits of renewables need to be operationalized. Populations struggling to recover their livelihoods after COVID-19 pandemic need to understand why they should support renewable energy solutions, particularly if such technologies are perceived to be costly, or have uncertain outcomes and non-specific benefits.

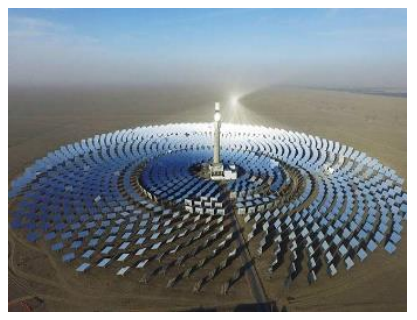

\section{Urban contexts:}

More comprehensive urban planning is needed to incorporate both renewable energy and naturebased solutions to make cities more resilient, addressing jointly the many issues shared by LAC coastal megacities-in energy planning full electrification of infrastructures and transport, deployment of advanced renewable technologies (e.g., Concentrated Solar Power: pictured above), re-use of industrial and municipal waste, retrofitting for renewables, improving access to cooling and safe cooking inside homes, and addressing water and air pollution.

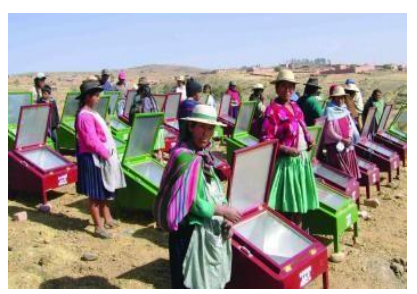

\section{Rural contexts:}

Insufficient attention has been paid to low-cost, small-scale energy solutions, including off-grid solar, which have the potential to bring crosssector benefits and address multiple SDGs simultaneously (e.g., re-use of bio-waste to replace costly chemical fertilizers used in agriculture; solutions that prevent slash \& burn; and clean cooking technologies (pictured above) that replace biomass to avoid deforestation and air pollution).

In rural indigenous contexts, recognition of cultural values, reciprocal knowledge exchange, and better access to information and capabilities (training) improve chances of project success. The uptake of renewables will likely be hindered when lines of communication are not established, when technical capacity is constrained and upskilling not planned for, and when information asymmetry emerges among the different sets of actors.

Indigenous and local knowledge have been increasingly recognized as an important source of climate knowledge and adaptation strategies $[10,11]$. Indigenous ways of understanding the changing climate can contribute to the evolving methodologies on climate-relevant data, as well as global adaptation and mitigation efforts (Table $\mathbf{3}$ ). 


\section{Table 3. Natural carbon sink opportunities}

- $49 \%$ of LAC area forested

- 935 million hectares total area

- 404 million occupied by around 40 million Indigenous and tribal peoples

- $22 \%$ of world's forests

- $5 \%$ carbon sink of global emissions

- 42.8 to 59.7 million metric tons (MtC) of $\mathrm{CO}_{2}$ emissions avoided annually [12-14]

Energy transitions and Sustainable Development Goals (SDGs). If local communities are expected to share in the benefits of such transitions, the recovery packages need to be linked to integrated pathways (i.e., sustainable development framework) to ensure that pre-existing gaps and vulnerabilities are addressed and resolved, rather than replicated and amplified. This implies accounting for the most pressing regional challenges: income inequalities (SDG 10), lack of innovation (SDG 9), and insecurity (SDG 16) [7]. Solving this trilemma calls for legal and institutional reforms, knowledge dissemination, and new levels of problem-solving capabilities-all of which require investment in the development of human capital, training, and upskilling, as well as research, science and innovation.

Science, Technology, and Innovation (STI) related to SDG 9 can help steer climate compatible development underpinned by a rapid uptake of renewables and decarbonization of the gas sector, in turn increasing productivity and energy efficiency while reducing costs. For example, if all thirty-one countries in the Caribbean sub-region move to
$90 \%$ clean energy by 2030 , this will not only benefit human and environmental health, but also result in annual savings of 9 billion in fuel costs [8].

If the focus of STI is expanded to address societal and environmental challenges, it can become a key driver toward progress on multiple SDGs [9].

Summary of findings. Since science and research communities are mostly excluded from arenas where political choices about energy development are made, the latest scientific knowledge (e.g., social energy research $[15,16])$ does not become inscribed in policy design, nor projects themselves. In turn, this precludes synergies between SDG 7 (latest low-carbon energy science), SDG 9 (innovation), SDG 10 (equality), and SDG 16 (improved institutions). Unequal local access to capabilities and opportunities compromises innovation and productivity [17], and this leads to an underachievement of SDG 9.

Going forward, more productive interactions are needed between the different forms of knowledge:

a) Local and international climate \& energy research community (latest science \& technology knowledge)

b) climate \& energy practitioners (private and public sector policy knowledge)

c) local communities (community, traditional, or indigenous knowledge) as potential prosumers (energy producers)

To fill the current need, and to avoid mismatch between problems and solutions [18], the author proposes to establish Research \& Training Centres (RTCS) at national levels that can serve as an interface between the three communities.

\section{Recommendations}

\section{Improve capabilities (RTCs)}

Research \& Training Centres (RTCS) at a national level are being proposed as collaborative spaces for climate-energy research [19]. Aside from conducting joint research and upskilling local talent, key functions of RTCs would be to communicate, demonstrate, and implement state-of-the-art climate compatible energy solutions based on contextualized technology assessment.

\section{Improve legal and institutional framework}

Climate and energy law: the linkage between the two is yet to be established; frameworks governing energy do not overlap with climate law.

Renewable energy law: currently not comprehensive; it may include some renewables, but leave out others, such as biomass, biofuels, or geothermal.
Targets on renewables: while established in most countries, it remains unclear how they will be applied in both short and long-term planning, and in both urban and rural development. At the interface between climate and energy, many cities do not have specific renewable energy targets integrated in city strategies, and they lack empowered, resilience offices with a mandate to act.

All-of-energy matrix approach to energy transitions is still missing (for economic growth to be compatible with climate goals, the energy transition needs to be transformative-i.e., the participation of renewables in the overall energy matrix cannot be just an add-on, but instead must replace fossil fuels [5]. 


\section{References}

[1] Damilola Ogunbiyi, Co-Chair of UN-Energy, and Special Representative of the UN SecretaryGeneral for Sustainable Energy for All.

[2] Washburn, C. \& Pablo-Romero. Measures to promote renewable energies for electricity generation in Latin American countries. Energy Policy. 2019.

[3] Balza et al. Lights on? Energy needs in Latin America and the Caribbean to 2040. Inter-American Development Bank. 2016.

[4] Juan Luis Dammert, Latin America director, Natural Resource Governance Institute. UN Global Roundtable. 25 May 2021.

[5] Pye et al. Shaping fossil fuel extraction strategies in developing countries in a decarbonizing world. 2021.

[6] Dobson et al. Ecology and economics for pandemic prevention. Science. 2020.

[7] SDG Index for Latin America and the Caribbean. Report. 2019.

[8] SEforALL. Recover Better with Sustainable Energy Guide for Caribbean Countries. 2020.

[9] STI. Guidebook for the preparation of Science, Technology, and Innovation for SDGs Roadmaps. 2020.

[10] UN Climate Change Conference. The Local Communities and Indigenous Peoples' Platform (LCIPP). https://unfccc.int/news/the-engagement-of-indigenous-peoples-and-local-communities-crucial-to-tackling-climate-crisis
[11] Escazú Agreement. Regional Agreement on Access to Information, Public Participation and Justice in Environmental Matters in Latin America and the Caribbean. United Nations Treaty Collection. 2018.

[12] IPBES. Global assessment report on biodiversity and ecosystem services of the Intergovernmental Science-Policy Platform on Biodiversity and Ecosystem Services. Bonn. 2019.

[13] FAO and FILAC. Forest governance by indigenous and tribal peoples. An opportunity for climate action in Latin America and the Caribbean. Santiago. FAO. 2021.

[14] Walker et al. The role of forest conversion, degradation, and disturbance in the carbon dynamics of Amazon indigenous territories and protected areas. PNAS. 2021.

[15] Jenkins, K. E. Towards impactful energy justice research. Energy Research \& Social Science. 2020.

[16] Sovacool, B.K., et al. Sociotechnical agendas: Reviewing future directions for energy and climate research. Energy Research \& Social Science. 2020.

[17] ECLAC (Economic Commission for Latin America and the Caribbean). The Inefficiency of Inequality. 2018.

[18] Jasanoff, S. Just transitions: A humble approach to global energy futures. Energy Research \& Social Science. 2018.

[19] Hampl, N. Negotiating Climate and Energy Futures: Prospects for Climate Compatible Recoveries in Latin America and the Caribbean" (forthcoming). The concept of RTCs is corroborated in the final manuscript.

\section{Notes}

\section{Climate Compatible Growth (CCG) pro-}

gramme: CCG is funded by the UK's Foreign Development and Commonwealth Office (FCDO) to support investment in sustainable energy and transport systems to meet development priorities in the Global South.

During the period of this research, the author was a recipient of a DOC Fellowship of the Austrian Academy of Sciences.

\section{Author Information:}

\section{Affiliation}

Department of Political Sciences, University of Vienna, Austria

Corresponding author

Email: norah16@univie.ac.at

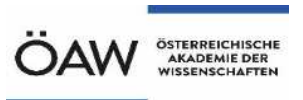

